\title{
$C_{0} \mathbf{I} \cdot \mathbf{R}^{\circ} \mathbf{P} \cdot \mathbf{E}^{\prime} \mathrm{E}$
}

Centre Interuniversitaire sur le Risque, les Politiques Économiques et l'Emploi

Cahier de recherche/Working Paper 12-13

\section{The Global Fight against Child Trafficking : How Can It Be Won?}

\author{
Sylvain Dessy \\ Caroline Orset \\ Legrand Yémélé Kana
}

Mars/March 2012

Dessy: Département d'économique et CIRPÉE, Université Laval, Québec, Canada sdes@ecn.ulaval.ca

Orset: Corresponding author. INRA-AgroParisTech, UMR Économie Publique, 16 rue Claude Bernard, F-75231 Paris Cedex 05. Tél. : +331 44087274 (Paris)

orset@agroparistech.fr

Yémélé Kana: Département d'économique et CIRPÉE, Université Laval, Québec, Canada legrand-yemele-kana.1@ulaval.ca

We are grateful to Yann Bramoullé and Philippe de Donder for helpful comments. We thank participants at the JAGV 2011 Conference held at the Universite Aix-Marseille II, and at the Canadian Economic Association 2011. 


\begin{abstract}
:
We study how countries can coordinate their national action plans so as to fight global child trafficking. As both the demand and supply of trafficked children are transboundary in scope, international cooperation may be necessary to mitigate cross-country externalities. We show that specialization is the main feature of international cooperation. We also show that the pattern of specialization depends only on the level of economic development of state-parties. In particular, specialization leads to asymmetric national action plans when state-parties have different levels of economic development: the governments of poorer countries specialize on fighting the supply of trafficked children from their territories, while the governments of richer countries specialize on fighting the demand arising within their territories.
\end{abstract}

Keywords: Child trafficking, Externalities, International cooperation, Cooperative equilibrium

JEL Classification: D62, F53, J47, O19 


\section{Introduction}

This paper explores the fundamental principles of a successful international coordination of national action plans aimed at curbing global child trafficking. Children are trafficked within and across borders in almost all countries, although children from Africa, Latin America, and South Asia are over-represented among the victims (UNICEF-IRC 2009). Exploitation of trafficking victims ranges from involvement in hazardous labor, sexual exploitation, domestic servitude, street begging, to criminal activities (UNICEFIRC 2008). As in the case of most criminal activities, concrete data on child trafficking are unavailable, but estimates do exist. For example, in 2002, the International Labor Organization (ILO) estimated that 1.2 million children are trafficked worldwide for the purpose of labor or sexual exploitation each year (UNICEF-IRC 2008). In its 2004 Trafficking in Persons Report covering the years 2004 to 2006, the US state Department estimated that every year 600,000 to 800,000 people are trafficked across international borders worldwide, including children. These figures suggest that child trafficking has become a global business, raising major concerns among national governments and the international community at large.

Global concern for child trafficking is firmly articulated in the United Nation's Palermo Protocol. As a supplement to the United Nations Convention against Transnational Organized Crime, the Palermo Protocol aims to (a) prevent and combat trafficking in persons, paying particular attention to women and children; (b) protect and assist the victims of such trafficking, with full respect for their human rights; and (c) promote cooperation among states parties in order to meet those objectives. ${ }^{1}$ However, ratification of this instrument of international cooperation is not universal; implementation is patchy; and lack of action to implement it remains a problem (UN-GIFT 2008). What is more, the reported complexity of the child trafficking business continues to impair practitioners' knowledge of what may work and what may not in getting states parties to cooperate effectively for the elimination of this phenomenon.

Conceptually, child trafficking can be construed as involving two separate economic operations. On one hand, there are operations involving the targeting of vulnerable children in a given state or region for abduction or recruitment and their illegal transportation to trading points within or across the border-upstream operations. We interpret these operations as supply-creating. On the other hand, there are operations involving the illegal adoption of unscrupulous production practices involving labor exploitation, which cre-

1. See United Nation (2000)' Palermo Protocol, available at http://www.segretariatosociale.rai.it/INGLESE/codici/tratta_esseri_umani/protocol_ing.pdf 
ate a demand for trafficked children whose labor is then exploited for profit-downstream operations. At a country level, a comprehensive national action plan may therefore involve fighting child trafficking on two battlefronts: an upstream (or supply) front where public action can aim to spread a safety net under potentially vulnerable children, and a downstream (or demand) front where such action can fight exploitation of children, for example by inspecting workplaces for illegal production practices intensive the use of trafficked children. Pressing questions thus arise: Are there gains from specialization among state parties involved in the global fight against child trafficking? If so, what is the pattern of this specialization? In other words, should all state parties do the same thing irrespective of their structural characteristics (richer or poorer)? These are the questions we address in this paper.

We develop a two-country model of child protection against child trafficking, highlighting two battlefronts against child trafficking. In the upstream front, the first line of defense consists of parental investment in child protection against vulnerability to trafficking. Success at this level tracks parental wealth. Vulnerable children are therefore those whose parents cannot afford to allocate household resources to child protection. This creates an incentive for the government to join the battle on this front, at least on equity grounds. Furthermore, if the demand for trafficked children were predominantly domestic, it would have been possible for the government to attack the demand as well. However, when child trafficking is transboundary, attacking demand may be ineffective, without the cooperation of the governments of foreign states. Moreover, even if the government ends up focusing exclusively on supply, how effective this policy will be is itself influenced both by the relative level of economic development of other countries and the actions of the governments of these countries. International coordination of states' national action plans may thus be necessary to mitigate this negative externality, and restore efficiency.

In our model, the object of international cooperation is therefore the prescription of the share of public funds the government of each country is to allocate to each of the two battlefronts. The goal of this international cooperation is construed as the minimization of the global incidence of child trafficking. To solve this minimization problem, we follow a two-step strategy. First, we characterize a global market equilibrium, which we define as the relative price that clears the global child trafficking market. This price is the link between upstream and downstream operations, and thus represents the mechanism through which cross-country externalities impact the effectiveness of each country's national action plan against child trafficking. Indeed, we show that, in each state, the 
equilibrium incidence of child trafficking is influenced by own-state policy actions as well as by foreign states' policy actions. In other words, policy actions in one state generate an externality (positive or negative) in the incidence of child trafficking in another state.

Second, we characterize the global incidence of child trafficking as the outcome of a cooperative equilibrium defined as the policy actions' pair that minimizes the global incidence of child trafficking. We derive the properties of the cooperative equilibrium thus defined by solving the model numerically. In doing so, we distinguish between two casescenarios. In one, parental and government actions in the upstream front are strategic substitutes, while in the other, there are strategic complements. In each case-scenario, we discuss international cooperation both between structurally similar states, and between structurally different states.

We show that specialization is the main feature of international cooperation. We also show that the pattern of specialization depend only on the level of economic development of state-parties. In particular, specialization leads to asymmetric national action plans when state-parties have different levels of economic development. The governments of poorer states should focus on fighting the supply of trafficked children from their territories, while richer countries should focus on fighting the demand for trafficked children within their territories. The underlying intuition is quite straightforward: the supply of trafficked children is higher, the poorer the economy while the demand for trafficked children is higher, the richer the economy. To the extent that child trafficking is a transboundary phenomenon, the high incidence of child vulnerability to trafficking in the poorer country generates a negative externality in the fight against demand in the richer country while the high demand for trafficked children in the richer country generates a negative externality in the fight against supply in the poorer country. Therefore, international cooperation best internalizes these cross-country externalities by mandating a pattern of complete specialization whereby the poorer country attacks the supply while the richer country attacks the demand.

Interestingly, when the economies of state parties are structurally similar, there may be multiple specialization profiles if both of them are sufficiently rich: each state can specialize its attack either on the supply-side (with the other doing the opposite) or on the demand-side (with the other doing the opposite). Cooperation yields symmetric national actions plans only when state-parties are equally poor. We also show that whether or not parental and government actions in the upstream front are strategic complements does not affect the patterns of specialization across state-parties, although it expectedly 
leads to different incidences of child trafficking globally.

To the best of our knowledge, our model is the first to directly address the issue of international coordination of national action plans against child trafficking, although general contributions to the child trafficking literature exist. For example, Dessy and Pallage (2005) analyze the determinants of children participation in the worst forms of child labor, and study their implications for the ratification of ILO Convention 182 on the worst forms of child labor. Rogers and Swinnerton (2008) analyze the welfare effects of combating exploitative child labor, in a context where poor and vulnerable families get tricked by unscrupulous entrepreneurs into releasing custody of their offspring in exchange for the often unfulfilled promise of a better future for these children. Each of these two previous models could be reinterpreted as a child trafficking model on its own right. However, it is not clear what their implications for international cooperation would be. Our contribution to this literature is thus to uncover the pillars of an efficient international cooperation in the global fight against child trafficking.

Our study also contributes to the literature on international cooperation and agreements (Barret 2001 and 2003; Boucher and Bramoullé 2010). Barrett (2001) investigates the size of a self-enforcing international environmental agreement and highlight asymmetries among countries as a key factor to self-enforcing agreements. Boucher and Bramoullé (2010) extend the model in Barret (2003) to investigate the impact uncertainty and risk aversion have on international agreements to supply global public goods. All these existing studies are primarily concerned with international cooperation for the production of global public goods (or public bads) with application to environmental economics. We contribute to this literature by focusing on international cooperation to combat child trafficking-a trans-boundary phenomenon. We follow Barret (2001) by distinguishing between symmetric state parties and asymmetric state parties in the exploration of the pillars of an efficient international coordination of national action plans against child trafficking.

The rest of this paper is structured as follows. Section 2 describes the environment, highlighting the coexistence of within-state child trafficking alongside its cross-border component. Section 3 discuss international cooperation when parental and government actions in the upstream front are strategic substitutes. Section 4 then extend the discussion to the case where parental and government actions in the upstream front are strategic complements. Finally, section 5 concludes. 


\section{The Setup}

Consider a world consisting of two states denoted $A$ and $B$, respectively. Each state is populated by a continuum one of households. Initially, a household includes an adult decision-maker and his unique child. In each state, households initially differ only with respect to their endowment $k$ of capital, which is drawn from a compact set, $\left[0, \bar{k}_{i}\right]$, where $0<\bar{k}_{i}<\infty$ in each state $i(i=A, B)$, according to a cumulative density function, $\Psi_{i}$, with strictly positive density $\psi_{i}(k)=\Psi_{i}^{\prime}(k)$, where $0<\bar{k}_{i}<\infty$ in each state $i(i=A, B)$. The cumulative density function (cdf) $\Psi_{i}^{\prime}$ and the boundary elements $\bar{k}_{i}$ $(i=A, B)$ may differ across states, so as to obtain per capita income differences across these states.

Cross-border child trafficking is the only trade link between the twostates, which otherwise are closed economies. In each state, a non-traded final good is produced. Adults in each state all work for firms producing the non-traded good. The market for trafficked children is international in scope, and thus allows for cross-border child trafficking for exploitation. In all markets, firms exhibit a price-taking behavior. Child trafficking consists of two types of operations, upstream and downstream operations. Because of opportunities for cross-border trafficking, our model highlights state-interdependencies with respect to the determinants of the incidence of child trafficking and discusses policy coordination between the two states.

\subsection{Household's problem}

In each state $i(i=A, B)$, a household-head (from here on, the parent) has preferences over own-consumption of the non-traded good, and over the safety of her unique child. The realized utility of a representative parent in state $i$ is given as follows:

$$
U(c)=(1-I \delta) c, \quad \delta \in(0,1)
$$

where $\delta$ is a measure of the disutility incurred by a parent if and when she loses her child to traffickers ${ }^{2}, c$, the quantity he or she consumes of the non-traded good, and $I \in\{0,1\}$, her realized status. A parent with status $I=0$ enjoys custody of his or her child, while a parent with status $I=1$ lost her child to traffickers and thus incurs a level of disutility equal to $\delta c$.

2. Obviously, this feature of parental preferences suggests that the level of disutility from the lost of a child is identical for all households, and all countries. While this may not necessarily be a feature of the reality, we abstract away from this complexity so as to keep the focus on the implications of cross-country interpendencies in child trafficking outcomes for efficient international cooperation against child trafficking. 
In each state $i$ and in every household, the parent is a factor supplier who sells labor to firms in exchange for a wage, $\omega_{i}$, and rents her capital endowment, $k$, to firms at a rental rate $r_{i}$. Given her income, she decides how much to consume of the non-traded good. At the same time, she decides whether or not to provide adequate protection to her unique child to shield the child against unscrupulous child traffickers. Assume it takes a quantity $\theta$ of the numeraire good to fully protect the child from becoming vulnerable to trafficking. One can think of $\theta$ as the level of resources needed to provide a child with adequate care-including adequate nutrition, lodging, and schooling. The parent's decision on child protection is thus a binary variable $x$ that takes the value $x=1$ if the parent elects to expend private resources in order to afford her offspring with adequate protection, and $x=0$ if she elects not to.

With this specification of the parent's child protection decision, we can next characterize the parent's realized status as follows: $I=\Gamma(x)$, such that

$$
\Gamma(x)=\left\{\begin{array}{lll}
0 & \text { if } & x=1 \\
I_{0} & \text { if } & x=0
\end{array}\right.
$$

where $I_{0}$ denotes a random variable described as follows:

$$
I_{0}=\left\{\begin{array}{lr}
0 & \text { with prob. } 1-\rho_{i} \\
1 & \text { with prob. } \quad \rho_{i}
\end{array}\right.
$$

In other words, $\rho_{i}$ is the conditional probability that a child left unprotected (i.e., $x=0$ ) falls victim to traffickers.

If we denote as $\bar{n}_{i}$ the total number of vulnerable children in state $i$, and by $n_{i u} \in$ $\left[0, \bar{n}_{i}\right]$, its total number of child trafficking victims, then the conditional probability, $\rho_{i}$, can be described as follows:

$$
\rho_{i}=\frac{n_{i u}}{\bar{n}_{i}}
$$

all $i, i=A, B$.

A household with net income $\omega_{i}+r_{i} k_{i}-T_{i}$ faces the following budget constraint:

$$
c+x \theta \leq \omega_{i}+r_{i} k_{i}-T_{i} \text { for all } i,
$$

where $T_{i} \in(0,1)$ denotes the level of the lump sum tax levied by the government of state $i$ on all households. Given our normalization of the population size in each state, $T_{i}$ is also total tax revenue available to the government in state $i$. As the utility function is strictly increasing, the representative parent's expected utility maximization problem can be stated as follows: 


$$
\max _{\langle x\rangle}[1-\delta \Gamma(x)]\left(\omega_{i}+r_{i} k_{i}-T_{i}-x \theta\right)
$$

which is obtained by substituting (5) into (1).

\subsection{Optimal Household Decision on Child Protection}

For each state $i$, consider a parent's decision on whether or not to expend a level of resources $\theta$ to afford her offspring with adequate protection against child traffickers. Using (3), we can write the expected utility of a parent who makes the decision $x$ as follows:

$$
V\left(x, k_{i}, \omega_{i}, r_{i}, \rho_{i}, T_{i}\right)=\left\{\begin{array}{cc}
\omega_{i}+r_{i} k_{i}-T_{i}-\theta & \text { if } \quad x=1 \\
\left(1-\rho_{i} \delta\right)\left(\omega_{i}+r_{i} k_{i}-T_{i}\right) & \text { if } \quad x=0
\end{array} .\right.
$$

We then write the net expected utility gain from choosing to protect the child (i.e., $x=1$ ) as follows:

$$
\vartheta\left(k_{i}, \omega_{i}, r_{i}, \rho_{i}, T_{i}\right) \equiv V\left(1, k_{i}, \omega_{i}, r_{i}, \rho_{i}, T_{i}\right)-V\left(0, k_{i}, \omega_{i}, r_{i}, \rho_{i}, T_{i}\right)
$$

When $\rho_{i}>0$, expression (7) can be used to obtain the following parametric specification of the parent's net utility gain from investing in child protection against traffickers:

$$
\vartheta\left(k_{i}, \omega_{i}, r_{i}, \rho_{i}, T_{i}\right)=\rho_{i} \delta\left(\omega_{i}+r_{i} k_{i}-T_{i}\right)-\theta
$$

Arguably, it is optimal for a parent with a level of wealth, $k$, in state $i$, to invest in child protection against traffickers if and only if:

$$
\vartheta\left(k, \omega_{i}, r_{i}, \rho_{i}, T_{i}\right)>0
$$

Observe from (8) that in an environment where there is no risk of child trafficking (i.e., $\left.\rho_{i}=0\right)$ it is never optimal for a parent to invest in child protection: if $\rho_{i}=0$, then $\vartheta\left(k_{i}, \omega_{i}, r_{i}, \rho_{i}, T_{i}\right)<0$. Since

$$
\frac{\partial \vartheta\left(k_{i}, \omega_{i}, r_{i}, \rho_{i}, T_{i}\right)}{\partial k_{i}}>0
$$

whenever $\rho_{i}>0$, only poverty can prevent altruistic parents from investing in child protection.

It can thus be shown that there exists a threshold parental wealth level, $k_{i}^{*}$, such that for all parents with levels of wealth $k_{i}$ such that $k_{i}>k_{i}^{*}, x=1$ is optimal while for all those with levels of wealth such that $k_{i}<k_{i}^{*}$, choosing $x=0$ is optimal instead, where 


$$
k_{i}^{*}=\frac{1}{r_{i}}\left[\left(\rho_{i} \delta\right)^{-1} \theta+T_{i}-\omega_{i}\right]
$$

all $i \in\{A, B\}$. In other words, the threshold, $k_{i}^{*}$, divides the population of state $i$ 's parents between non-investors - in total number $\Psi^{i}\left(k_{i}^{*}\right)$, — and investors - in total number $1-\Psi^{i}\left(k_{i}^{*}\right)$.

\subsection{Child's Vulnerability to Trafficking}

Vulnerability factors associated with child trafficking are often tied to such child protection concerns as child discrimination based on gender, dysfunctional families, violence, and abuse in the community, at home, and a lack of livelihood opportunities for children (UNICEF's IRC Report 2009). While all these factors matter for child vulnerability to trafficking, both common sense and empirical evidence, however, point to poverty either at the family, community, or country level as the foundation of most these concerns. For example, in general, a parent with enough resources to go around may have little incentive to discriminate between her children; and even if she does, the resulting effect on the discriminated child vulnerability is likely to be small compared to what it would have been had the parent been poorer. Likewise, a family that lives in a community characterized by child abuse and violence may not stick around if it can afford to move to a safer community to afford its children more protection. Thus only poverty can prevent this family from either protecting its offspring in this community or moving to a safer community. This justifies why we model child's vulnerability to trafficking as being rooted in poverty (as determined by $\omega_{i}, r_{i}, k_{i}$ ).

A child vulnerability to trafficking can take several forms. But what we have in mind is a trafficking process whereby a child with no adequate family support has to fend for herself, in which case she is likely to fall victim to unscrupulous traffickers who may then abduct and transport her to trading points either domestically (within-state child trafficking) or in a foreign state (cross-border child trafficking).

Next, consider the total number of children vulnerable to trafficking, $\bar{n}_{i} \in[0,1]$. Given our normalization of the household size, we know that the cardinality of the set of households unable to invest $\theta$ in child protection is identical to the number of vulnerable children in the state. Therefore, we have that

$$
\bar{n}_{i}=\Psi\left(k_{i}^{*}\right)
$$

where $k_{i}^{*}$ is as defined in (10). Indeed from (10) it follows that factors accounting for 
cross-country differences in child's vulnerability to trafficking include $r_{i}, \rho_{i}, \omega_{i}$, and $T_{i}$. The following proposition therefore summarizes our sensitivity analysis with respect to the determinants of child vulnerability.

Proposition 1. Parents tend to invest less in child protection when the risk of child trafficking, $\rho_{i}$, is lower, and they are poorer, in the sense of having a lower net income as determined by $r_{i}, \omega_{i}$, and $T_{i}$.

Observe that $\rho_{i}, \omega_{i}$, and $r_{i}$ all are endogenous, and thus represent potential vehicles of cross-border effects on the domestic incidence of child vulnerability to trafficking. Therefore to gain a more complete understanding of the determinants of the number of vulnerable children in state $i$, we must first compute the equilibrium levels of $\rho_{i}, \omega_{i}$, and $r_{i}$. This will require a characterization of a general equilibrium for this two-state economy. The next steps take us toward this objective. From this point on, upstream variables are indexed by $u$ while downstream ones are indexed by $d$.

\subsection{Child Trafficking: Upstream Operations}

Recall that upstream operations in child trafficking include the recruiting and transporting of vulnerable children to trading points, where victims will be offered to private firms for exploitation, in exchange for a trafficking fee. We are not particularly interested in the individual identity of those performing these operations, but rather in the determinants of the viability of these operations. Therefore, we assume without loss of generality that upstream operations are carried out by perfectly competitive firms using capital only. This assumption is based upon ample evidence that capital is very important in the transporting and harboring of trafficking victims. More specifically, aircraft, boat, rail, ferry and automobiles may be used to take victims to the country of destination (UN-GIFT 2008). Capital may also be important for forgery of documents, and acts of coercion against the victims (guns, chains, etc.).

On the upstream battlefront, therefore, the representative firm uses capital, $K_{i u}$, to snatch away vulnerable children while the government invests a level of public funds, $g_{i u}$, to shield or rescue these children. The outcome of this battle between the representative firm and the government is reflected in the relative share, $\chi\left(g_{i u}, \bar{n}_{i}, K_{i u}\right)$, of vulnerable children that traffickers are able to snatch away. Thus, the representative firm's output, $n_{i u}$, which is the total number of trafficking victims, can be described as follows:

$$
n_{i u}=\chi\left(g_{i u}, \bar{n}_{i}, K_{i u}\right) \bar{n}_{i}, \quad \text { all } i \in\{A, B\},
$$


all $i$, where $\chi\left(g_{i u}, \bar{n}_{i}, K_{i u}\right)$ denotes the proportion of vulnerable children who effectively fall victim to traffickers. The function $\chi($.$) reflects the productivity of the trafficking tech-$ nology used, where $K_{i u}$ is the level of capital used by the representative child trafficker. We make the following assumption:

A.1. The function $\chi($.$) is given as follows:$

$$
\chi\left(g_{i u}, \bar{n}_{i}, K_{i u}\right)=\frac{\varepsilon_{u} \bar{n}_{i}^{\varsigma} K_{i u}}{1+g_{i u}}
$$

where $\varsigma \in[-1,1]$, and $\varepsilon_{u}$ is a positive parameter.

Observe that using (4) and (12), we can write the conditional probability that a vulnerable child falls victim to traffickers as follows:

$$
\rho_{i}=\chi\left(g_{i u}, \bar{n}_{i}, K_{i u}\right)
$$

all $i$. As an implication, we obtain the probability that a vulnerable child avoid falling into the traffickers' net as follows:

$$
\sigma_{i}=1-\chi\left(g_{i u}, \bar{n}_{i}, K_{i u}\right)
$$

with $\rho_{i}+\sigma_{i}=1$. Therefore, using (13), we obtain the following cross-partial derivative:

$$
\frac{\partial^{2} \sigma_{i}}{\partial g_{i u} \partial \bar{n}_{i}}=\frac{\varsigma \varepsilon_{u} K_{i u}}{\left(1+g_{i u}\right)^{2} \bar{n}_{i}^{1-\varsigma}} .
$$

An increase in $g_{i u}$ corresponds to an increase in the level of public investment in child protection against upstream trafficking operations. By comparison, a decrease in $\bar{n}_{i}$ corresponds to an increase in the number of parents who invest in child protection against vulnerability to trafficking. An important question thus is: how does public investment and parental investment interact in the fight against upstream child trafficking operations? Using (14), we can easily show that the answer to this question clearly depends on $\varsigma$. We then obtain the following definition:

Definition 1. Parental investment and public investment are strategic substitutes in the fight against upstream child trafficking operations if and only if $\varsigma \geq 0$, and are strategic complements if and only if $\varsigma<0$.

Indeed, when $\varsigma>0$ (respectively, $\varsigma<0$ ), expression $(14)$ is positive (respectively, negative), which correspond to strategic substitutability (respectively, complementarity) in this case. To close our discussion of upstream child trafficking operations, we characterize 
the zero-profit condition implied by perfect competition. Letting $p$ denote the price at which a trafficking victim is traded to firms in downstream operations, we can write the representative upstream firm's profit as follows:

$$
\Pi_{i u}=p n_{i u}-r_{i u} K_{i u},
$$

all $i$. Substituting (12) and (13) in (15), re-arranging, yields this profit function as follows:

$$
\Pi_{i u}=\left(\frac{p \varepsilon_{u} \bar{n}_{i}^{1+\varsigma}}{1+g_{i u}}-r_{i u}\right) K_{i u}
$$

all $i$, where $r_{i u}$ denotes the rental rate charged to the representative firm for capital rented. Since capital is the only input into child trafficking operations, perfect competition erases all profit: $\Pi_{i u}=0, i$. It can then be shown that the zero-profit condition holds if and only if :

$$
r_{i u}=\frac{p \varepsilon_{u} \bar{n}_{i}^{1+\varsigma}}{1+g_{i u}}
$$

all $i$.

\subsection{Child Trafficking: Downstream Operations}

We model downstream child trafficking operations as involving the exploitation of trafficking victims' labor in the production process of the non-traded good. This modeling strategy is supported by the evidence that unscrupulous employers who generate a demand for trafficked children are a significant element in the trafficking chain and are considered traffickers, because they have received trafficked children and thus conform to the Palermo Protocol's definition of trafficking (ILO-IPEC 2009). Forced labor - also known as modern-day slavery - is a good example of the trafficked children's involvement in productive activities. However, as children are not necessarily the productive equals of adults, we convert a child productivity in the non-traded good sector to its adult equivalent, as in Basu and Van (1998). Therefore in each state $i$, we model the aggregate production function for the non-traded good as exhibiting constant return to scale to capital, $K_{i d}$, and efficiency units of labor, $H_{i d}$ :

$$
Y_{i d}=K_{i d}^{\gamma} H_{i d}^{1-\gamma}, \quad 0<\gamma<1
$$

where

$$
H_{i d}=L_{i d}+\alpha_{i} n_{i d}
$$


$L_{i d}$ denotes the number of hired adults, $n_{i d}$, the number of trafficked children exploited by the representative firm, and $\alpha_{i} \geq 0$, the adult-equivalent of an exploited child's labor productivity.

The direct cost to the representative firm of exploiting trafficked children thus is $p n_{i d}$, which is deducted from the firm's revenue. In each state $i$ therefore, the representative firm in the non-traded good sector solves the following problem: ${ }^{3}$

$$
\max _{\left\langle K_{i d}, L_{i d}\right\rangle}\left\{K_{i d}^{\gamma} H_{i d}^{1-\gamma}-r_{i d} K_{i d}-\omega_{i} L_{i d}-p n_{i d}\right\} .
$$

Resource constraints in state $i$ are given as follows:

$$
\begin{aligned}
K_{i d}+K_{i u} & \leq \int_{0}^{\bar{k}_{i}} k_{i} \psi\left(k_{i}\right) d k_{i}=\widetilde{k}_{i} \\
L_{i d} & \leq 1 .
\end{aligned}
$$

As trafficked children are the only "good" traded between the two states, the tradebalance condition for trafficked children is

$$
\sum_{i=A, B} n_{i d}=\sum_{i=A, B} n_{i u}
$$

Profit-maximization by the representative firm leads to the following factor pricing rules under market-clearing:

$$
\begin{aligned}
\omega_{i} & =(1-\gamma)\left(\frac{\widetilde{k}_{i}-K_{i u}}{1+\alpha_{i} n_{i d}}\right)^{\gamma} \\
r_{i d} & =\gamma\left(\frac{\widetilde{k}_{i}-K_{i u}}{1+\alpha_{i} n_{i d}}\right)^{\gamma-1} \\
p & =\alpha_{i}(1-\gamma)\left(\frac{\widetilde{k}_{i}-K_{i u}}{1+\alpha_{i} n_{i d}}\right)^{\gamma}
\end{aligned}
$$

all $i$.

\subsection{National Action Plan against Child Trafficking}

In each state $i$, the national action plan against child trafficking involves a twobattlefront attack on child trafficking. Because of cross-border trafficking, child vulnerability to trafficking in any given state can become an international concern, calling

3. The profit function in (20) does not include expenditures on trafficked children's maintenance, including food and clothing. While adding these maintenance costs would increase our model's connection to reality, it would not, however, bring any qualitative improvement to our results. 
for cooperation among the states as an effective strategy for curbing child trafficking and exploitation.

In each state $i$, we assume a proportion, $\phi_{i} \in[0,1]$, of the tax revenue collected is allocated to fighting child trafficking on the upstream front while the remaining proportion, $1-\phi_{i}$, is allocated to fighting it on the downstream front.

Fighting upstream child trafficking operations can take various forms including targeting vulnerable families for conditional cash transfer or building schools within vulnerable communities so as to limit the risk factors that contribute to vulnerable children being easily lured by unscrupulous entrepreneurs. Prevention of child trafficking can also take the form of implementation of a legislation mandating the registration, licensing and monitoring of recruitment agencies, temporary human resource bureaus and other agents involved in recruiting, organizing and facilitating labor migration (ILO-IPEC 2009). To the extent that the government is subject to a balanced budget legislation, the level of public funds allocated to the upstream battlefront against child trafficking thus is:

$$
g_{i u}=\phi_{i} T_{i}
$$

where $T_{i}$ is total tax revenue in state $i$, all $i$.

On the downstream front, public action to fight child exploitation is based upon the recognition that identifying exploitative employers and bringing them to justice is an important tool for curbing the demand for trafficked children. This may occur through workplace inspectors who identify cases of child labor/child trafficking and use the power of labor laws to bring exploiters to justice. Such public action thus may affect guilty firms through a reduction in the level of child productivity. For instance, depending on the frequency with which government officials inspect workplaces, unscrupulous firm managers may be forced to reduce the number of hours worked by their victims, so as to avoid detection by government inspectors, thus leading to a decline in children's productivity. In other words, the outcome of the battle between the government of state $i$ and exploitative firms is reflected in the level of the child productivity parameter, $\alpha_{i}$. More formally,

$$
\alpha_{i}=\frac{\varepsilon_{d}}{1+g_{i d}}
$$

where $\varepsilon_{d}>0$, and

$$
g_{i d}=\left(1-\phi_{i}\right) T_{i}
$$

The term $\varepsilon_{d}$ is assumed to be identical in both states, as is $\varepsilon_{u}$. For the sake of simplicity and to keep the focus of international coordination of anti-child trafficking 
policies, we also abstract away from the political economy of taxation in each state by making the following assumption:

A.2. Given the vector of structural fundamentals of each state, $\left(\bar{k}_{i}, \Psi^{i}\right)$, and for all $i=$ $A, B$, the lump sum tax financing the fight against child trafficking and exploitation, $T_{i}$, is given by

$$
T_{i}=\beta \bar{k}_{i}^{\epsilon}, \quad \beta, \epsilon>0 .
$$

Next, we characterize a market equilibrium for the two-State global economy.

\section{Market Equilibrium}

In this section we characterize, for each State $i$, the incidence of child vulnerability to trafficking, the supply of, as well as the demand for, trafficked children.

\subsection{Incidence of Child Vulnerability to Trafficking}

In each state $i$, child-trafficking and the production of the non-traded good are competing claims for capital use. Since capital is perfectly mobile across these two sectors, rental rates equalization is clearly a feature of the market equilibrium in each state:

$$
r_{i u}=r_{i d}
$$

all $i(i=A, B)$. We use this rental rates equalization condition to establish the following Proposition:

Proposition 2. Suppose that for all $i$,

$$
\Psi^{i}(k)=\frac{k}{\bar{k}_{i}},
$$

and

$$
p+\left(1+g_{i u}\right)^{\frac{1}{1+\varsigma}} p^{-\mu} \bar{k}_{i} a_{i}-\alpha_{i} T_{i}>0
$$

Then,

(i) the equilibrium number of vulnerable children in state $i$ is given by $\bar{n}_{i} \equiv \bar{N}\left(\phi_{i}, \bar{k}_{i}, p\right)$, with

$$
\bar{N}\left(\phi_{i}, \bar{k}_{i}, p\right)=\left[\frac{\gamma\left(1+g_{i u}\right)\left[(1-\gamma) \alpha_{i}\right]^{\frac{1-\gamma}{\gamma}}}{\varepsilon_{u} p^{\frac{1}{\gamma}}}\right]^{\frac{1}{1+\varsigma}}
$$

and 
(ii) the conditional probability that a vulnerable child falls victim to traffickers is $\rho_{i} \equiv$ $\varrho\left(\phi_{i}, \bar{k}_{i}, p\right)$, with

$$
\varrho\left(\phi_{i}, \bar{k}_{i}, p\right)=\frac{\alpha_{i} \bar{\theta}}{p+\left(1+g_{i u}\right)^{\frac{1}{1+\varsigma}} p^{-\mu} \bar{k}_{i} a_{i}-\alpha_{i} T_{i}}
$$

where

$$
\begin{aligned}
\mu & =\frac{1+(1-\gamma)(1+\varsigma)}{(1+\varsigma) \gamma} \\
a_{i} & =\left[\varepsilon_{u}^{-1} \gamma^{2+\varsigma}\right]^{\frac{1}{1+\varsigma}}[(1-\gamma)]^{\frac{(1-\gamma)(2+\varsigma)}{(1+\varsigma) \gamma}} \alpha_{i}^{\frac{2+\varsigma-\gamma}{(1+\varsigma) \gamma}} \\
\bar{\theta} & =\theta / \delta
\end{aligned}
$$

Proof. The proof follows in several steps. First, from (31), substituting in (17) and (25) yields:

$$
\frac{p \varepsilon_{u} \bar{n}_{i}^{1+\varsigma}}{1+g_{i u}}=\gamma\left(\frac{K_{i d}}{1+\alpha_{i} n_{i d}}\right)^{\gamma-1}
$$

Solving the equation (39) using the capital availability constraint yields the following relative factor intensity in downstream production operations:

$$
\frac{\widetilde{k}_{i}-K_{i u}}{1+\alpha_{i} n_{i d}}=\left[\frac{\left(1+g_{i u}\right) \gamma}{p \varepsilon_{u} \bar{n}_{i}^{1+\varsigma}}\right]^{\frac{1}{1-\gamma}} .
$$

Substituting (40) in (24) and (26), rearranging, yields

$$
\begin{aligned}
\omega_{i} & =(1-\gamma)\left[\frac{\left(1+g_{i u}\right) \gamma}{p \varepsilon_{u} \bar{n}_{i}^{1+\varsigma}}\right]^{\frac{\gamma}{1-\gamma}} \\
p & =\alpha_{i}(1-\gamma)\left[\frac{\left(1+g_{i u}\right) \gamma}{p \varepsilon_{u} \bar{n}_{i}^{1+\varsigma}}\right]^{\frac{\gamma}{1-\gamma}} .
\end{aligned}
$$

Next, solving (42) for $\bar{n}_{i}$ given $\left(\phi_{i}, p\right)$ yields

$$
\bar{n}_{i}=\left[\varepsilon_{u}^{-1} \gamma\left(1+g_{i u}\right)\right]^{\frac{1}{1+\varsigma}}\left[(1-\gamma) \alpha_{i}\right]^{\frac{1-\gamma}{(1+\varsigma) \gamma}} p^{-\frac{1}{(1+\varsigma) \gamma}}
$$

or

$$
\varepsilon_{u} p \bar{n}_{i}^{1+\varsigma}=\left[\frac{(1-\gamma) \alpha_{i}}{p}\right]^{\frac{1-\gamma}{\gamma}}\left(1+g_{i u}\right) \gamma .
$$

This establishes part (i) of Proposition 2. 
To establish part (ii), consider (17) and (41). Substituting in (44), rearranging, yields:

$$
\begin{aligned}
\omega_{i} & =\alpha_{i}^{-1} p \\
r_{i} & =\gamma\left[\frac{(1-\gamma) \alpha_{i}}{p}\right]^{\frac{1-\gamma}{\gamma}} .
\end{aligned}
$$

Finally substituting (45) and (46) into (10), again rearranging, yields

$$
k_{i}^{*}=\frac{1}{\gamma}\left[\frac{p}{(1-\gamma) \alpha_{i}}\right]^{\frac{1-\gamma}{\gamma}}\left[\left(\rho_{i} \delta\right)^{-1} \theta+T_{i}-\alpha_{i}^{-1} p\right] .
$$

Next, we compute the conditional probability, $\rho_{i}$, that a vulnerable child falls victim to traffickers. First, by definition, the incidence of child vulnerability to trafficking in State $i$ is $\bar{n}_{i}=\Psi\left(k_{i}^{*}\right)$. Second, from (43), we have that

$$
\bar{n}_{i}=\Psi^{i}\left(\frac{1}{\gamma}\left[\frac{p}{(1-\gamma) \alpha_{i}}\right]^{\frac{1-\gamma}{\gamma}}\left[\left(\rho_{i} \delta\right)^{-1} \theta+T_{i}-\alpha_{i}^{-1} p\right]\right) .
$$

Finally, combining (32), (43) and (48), rearranging, yields the following equation:

$$
\left(\rho_{i} \delta\right)^{-1} \theta \alpha_{i}+\alpha_{i} T_{i}-p=\bar{k}_{i} a_{i}\left(1+g_{i u}\right)^{\frac{1}{1+\varsigma}} p^{-\mu},
$$

where

$$
\begin{aligned}
\mu & =\frac{1+(1-\gamma)(1+\varsigma)}{(1+\varsigma) \gamma} \\
a_{i} & =\left[\varepsilon_{u}^{-1} \gamma^{2+\varsigma}\right]^{\frac{1}{1+\varsigma}}[(1-\gamma)]^{\frac{(1-\gamma)(2+\varsigma)}{(1+\varsigma) \gamma}} \alpha_{i}^{\frac{2+\varsigma-\gamma}{(1+\varsigma) \gamma}}
\end{aligned}
$$

Solving this equation for $\rho_{i}$ then yields the result. This completes the proof.

Proposition 2 is established in the context of a uniform probability distribution of agents across wealth levels in each state. This is purely a simplifying assumption, made without loss of generality. A number of important remarks can be derived from Proposition 2 through partial differentiation of (34) and (35) respectively:

Remark 1. In any state $i$, when financed by an income tax, public investment aimed at mitigating upstream child trafficking operations tends to (i) increase the number of vulnerable children (i.e., $\partial \bar{n}_{i} / \partial g_{i u}>0$ ) and (ii) decrease the conditional probability that a vulnerable child will fall victim to traffickers (i.e., $\left.\partial \rho_{i} / \partial g_{i u}<0\right)$.

The above remark is consistent with the well-documented fact that when financed by an income tax, public policy always has a trade-off: it corrects one problem by creating another. Its success therefore depends on how high or low this trade-off is. 
Remark 2. For a vulnerable child, the likelihood of falling victim to traffickers is lower the wealthier the country: $\partial \rho_{i} / \partial \bar{k}_{i}<0$.

The intuition underlying this result is quite straightforward, and can be derived using expressions (12), (13), and (17). First, observe that since by definition the likelihood of falling victim to traffickers is $\rho_{i}=n_{i u} / \bar{n}_{i}$, from (12), we have that $\rho_{i}=\chi\left(g_{i u}, \bar{n}_{i}, K_{i u}\right)$, which, using (13) can be shown to be equal to

$$
\rho_{i}=\frac{\varepsilon_{u} \bar{n}_{i}^{\varsigma} K_{i u}}{1+g_{i u}}
$$

Second, since $\bar{n}_{i}=\Psi\left(k_{i}^{*}\right)$, it follows from (32) that $\partial \bar{n}_{i} / \partial \bar{k}_{i}<0$, implying that wealthier countries unsurprisingly have a lower incidence of child vulnerability to trafficking than poorer countries. Third, from (17), $\partial \bar{n}_{i} / \partial \bar{k}_{i}<0$ implies that $\partial r_{i} / \partial \bar{k}_{i}<0$. In other words, the return to capital in upstream child trafficking operations is lower in wealthier, than in poorer, countries. Therefore, upstream child trafficking operations taking place in wealthier countries will attract less capital than those taking place in poorer countries: $\partial K_{i u} / \partial \bar{k}_{i}<0$. It therefore follows that the likelihood of falling victim to traffickers is lower in wealthier, than in poorer, countries: $\partial \rho_{i} / \partial \bar{k}_{i}<0$.

Next, taking the partial derivative of (35) with respect to $p$ yields

$$
\frac{\partial \rho_{i}}{\partial p}=-\frac{\alpha_{i} \bar{\theta}\left[p^{(1+\mu)}-\mu\left(1+g_{i u}\right)^{\frac{1}{1+\varsigma}} a_{i} \bar{k}_{i}\right]}{\left[p+\left(1+g_{i u}\right)^{\frac{1}{1+\varsigma}} p^{-\mu} \bar{k}_{i} a_{i}-\alpha_{i} T_{i}\right]^{2} p^{(1+\mu)}} .
$$

Given $\mu$, and for $\bar{k}_{i}$ sufficiently large, the following inequality can easily obtain:

$$
p^{1+\mu}-\mu\left(1+g_{i u}\right)^{\frac{1}{1+\varsigma}} a_{i} \bar{k}_{i}<0,
$$

all $i$. Therefore, $\partial \rho_{i} / \partial p>0$ :

Remark 3. If in each state $i$ condition (50) is satisfied, then an increase in the market price of a trafficked child raises the conditional probability that a vulnerable child will be trafficked: $\partial \rho_{i} / \partial p>0$.

The intuition underlying this remark is quite straightforward. A higher price signals that child trafficking is a very lucrative business, which then attracts more capital into upstream child trafficking operations, thus leading to a higher likelihood that a vulnerable child will fall victim to traffickers. 


\subsection{Incidence of Child Trafficking}

In this sub-section, we compute the incidence of child trafficking in each state. By the application of the law of large numbers, this incidence is given by $n_{i u}=\rho_{i} \bar{n}_{i}$, where $\rho_{i}$ denotes the conditional probability that a vulnerable child falls victim to traffickers. From Proposition 2, it therefore follows that $n_{i u} \equiv N^{o}\left(\phi_{i}, \bar{k}_{i}, p\right)$, with

$$
N^{o}\left(\phi_{i}, \bar{k}_{i}, p\right)=\frac{\lambda_{i}\left(1+g_{i u}\right)^{\frac{1}{1+\varsigma}} p^{-\frac{1}{(1+\varsigma) \gamma}}}{p+\left(1+g_{i u}\right)^{\frac{1}{1+\varsigma}} p^{-\mu} \bar{k}_{i} a_{i}-\alpha_{i} T_{i}},
$$

where

$$
\lambda_{i}=\left(\varepsilon_{u}^{-1} \gamma\right)^{\frac{1}{1+\varsigma}}(1-\gamma)^{\frac{1-\gamma}{(1+\varsigma) \gamma}} \alpha_{i}^{\frac{1+\gamma \varsigma}{(1+\varsigma) \gamma}} \bar{\theta}
$$

A number of important observations can be derived from (51):

Remark 4. The incidence of child trafficking is always lower the wealthier the country: $\partial n_{i u} / \partial \bar{k}_{i}<0$.

The underlying intuition is quite straightforward. The incidence of child vulnerability to trafficking is smaller in wealthier countries because more families can afford to protect their children against vulnerability to trafficking. A lower incidence of child vulnerability in turn lower the return to capital in upstream child trafficking operations, thus driving capital away. As capital is key to the intensity of child trafficking activity, the result is a lower incidence of child trafficking.

Next, taking the partial derivative of (51) with respect to $p$, rearranging, yields:

$$
\frac{\partial n_{i u}}{\partial p}=\frac{\lambda_{i}\left(1+g_{i u}\right) \zeta(p)}{(1+\varsigma) \gamma\left[p+\left(1+g_{i u}\right)^{\frac{1}{1+\varsigma}} p^{-\mu} \bar{k}_{i} a_{i}-\alpha_{i} T_{i}\right]^{2}}
$$

where

$$
\zeta(p)=\tau p^{-\frac{1}{\gamma}}\left[\left(1+g_{i u}\right)^{\frac{1}{1+\varsigma}} a_{i} \bar{k}_{i} f(\varsigma)-p^{1+\mu}+\frac{\alpha_{i} T_{i} p^{\mu}}{1+\gamma(1+\varsigma)}\right]
$$

and

$$
\begin{aligned}
\tau & =\frac{[1+\gamma(1+\varsigma)]}{\gamma(1+\varsigma)} \\
f(\varsigma) & =\frac{(1-\gamma)(1+\varsigma)}{1+\gamma(1+\varsigma)} .
\end{aligned}
$$

The term $\zeta(p)$ is strictly positive if 


$$
\left(1+g_{i u}\right)^{\frac{1}{1+\varsigma}} a_{i} \bar{k}_{i} f(\varsigma)-p^{1+\mu} \geq 0 .
$$

Therefore, the following Remark is also straightforward:

Remark 5. If in each state $i$ condition (52) is satisfied, then an increase in the market price of a trafficked child raises the incidence of child trafficking in state $i: \partial n_{i u} / \partial p>0$.

However less straightforward is the effect of an increase in public investment aimed at combating upstream child trafficking operations, $g_{i u}$. Indeed, taking the partial derivative of (51) with respect to $g_{i u}$, ceteris paribus, yields:

$$
\frac{\partial n_{i u}}{\partial g_{i u}}=\frac{\left(p-\alpha_{i} T_{i}\right) \lambda_{i} p^{-\frac{1}{\gamma}}}{\left[p+\left(1+g_{i u}\right)^{\frac{1}{1+\varsigma}} p^{-\mu} \bar{k}_{i} a_{i}-\alpha_{i} T_{i}\right]^{2}} .
$$

If

$$
p>\alpha_{i} T_{i},
$$

then $\partial n_{i u} / \partial g_{i u}>0$. Only when

$$
p<\alpha_{i} T_{i}
$$

will this partial derivative be negative : $\partial n_{i u} / \partial g_{i u}<0$. Hence the following Remark:

Remark 6. Attacking upstream child trafficking operations is effective at reducing the incidence of child trafficking only when the trading price $p$ is relatively small.

A lower trading price implies that the demand for trafficked children is low. This Remark thus implies that factors that raise the demand for trafficked children can make it hard to fight upstream child trafficking operations, while those that lowers it can make it easier. Hence the need to fight child trafficking operations on both fronts. In this section, we define key endogenous variables along with the conditions these variables must satisfy in equilibrium. We begin with factor prices, $r_{i}$ and $\omega_{i}$, as these determine the number of children vulnerable to trafficking.

\subsection{Equilibrium Price}

We are now ready to characterize the equilibrium relative price of a trafficked child, $p$, given the fundamentals of this two-state global economy, as determined by the level of wealth of each state (proxied by $\bar{k}_{i}$ ), and its public policy framework (proxied by $\phi_{i}$, where $i=A, B)$. To characterize this trading price, $p$, we first must specify the excess 
demand function for trafficked children in this international environment.

From (23), we know that $\sum_{i} n_{i u}$ denotes the global supply of trafficked children and $\sum_{i} n_{i u}$, its global demand. Therefore, the global excess demand, $\chi\left(p, \phi_{A}, \phi_{B}, \bar{k}_{A}, \bar{k}_{B}\right)$, is given by

$$
\chi\left(p, \phi_{A}, \phi_{B}, \bar{k}_{A}, \bar{k}_{B}\right)=\sum_{i} n_{i d}-\sum_{i} N^{o}\left(p, \phi_{i}, \bar{k}_{i}\right)
$$

where $N^{o}\left(p, \phi_{i}, \bar{k}_{i}\right)$ is as defined in $(51)$.

To complete the characterization of the excess demand function, it remains to compute $n_{i d}$, for all $i$ :

Proposition 3. The demand for trafficked children in state $i$ is given by $n_{i d} \equiv N^{d}\left(p, \phi_{i}, \bar{k}_{i}\right)$ :

$$
N^{d}\left(p, \phi_{i}, \bar{k}_{i}\right)=\left[\frac{\bar{k}_{i}}{2}-K^{u}\left(\phi_{i}, \bar{k}_{i}, p\right)\right]\left[\frac{(1-\gamma) \alpha_{i}^{1-\gamma}}{p}\right]^{\frac{1}{\gamma}}-\alpha_{i}^{-1}
$$

where

$$
K^{u}\left(p, \phi_{i}, \bar{k}_{i}\right)=\left[\frac{\left(1+g_{i u}\right)^{\frac{1}{\varsigma}} p^{\frac{1}{\gamma}}}{\gamma \varepsilon_{u}^{\frac{1}{\varsigma}}\left[(1-\gamma) \alpha_{i}\right]^{\frac{1-\gamma}{\gamma}}}\right]^{\frac{\varsigma}{1+\varsigma}} \varrho\left(p, \phi_{i}, \bar{k}_{i}\right)
$$

and $\varrho\left(p, \phi_{i}, \bar{k}_{i}\right) \equiv \rho_{i}$, all $i$.

Proof. Consider (40). Substituting in (44), using (32), and rearranging, yields the demand for trafficked children as follows in State $i$ :

$$
n_{i d}=\left(\frac{\bar{k}_{i}}{2}-K_{i u}\right)\left[\frac{(1-\gamma) \alpha_{i}^{1-\gamma}}{p}\right]^{\frac{1}{\gamma}}-\alpha_{i}^{-1},
$$

all $i$. Next, from (49), we have that

$$
K_{i u}=\frac{\varrho\left(p, \phi_{i}, \bar{k}_{i}\right)}{\frac{\varepsilon_{u}}{1+g_{i u}} \bar{n}_{i}^{\varsigma}}
$$

Using (34), we have that

$$
\frac{\varepsilon_{u}}{1+g_{i u}} \bar{n}_{i}^{\varsigma}=\left(\frac{\varepsilon_{u}}{1+g_{i u}}\right)^{\frac{1}{1+\varsigma}}\left[\frac{\gamma\left[(1-\gamma) \alpha_{i}\right]^{\frac{1-\gamma}{\gamma}}}{p^{\frac{1}{\gamma}}}\right]^{\frac{\varsigma}{1+\varsigma}} .
$$

Combining (57) and (58) yields 


$$
K_{i u} \equiv K^{u}\left(p, \phi_{i}, \bar{k}_{i}\right)=\left[\frac{\left(1+g_{i u}\right)^{\frac{1}{\varsigma}} p^{\frac{1}{\gamma}}}{\gamma \varepsilon_{u}^{\frac{1}{\varsigma}}\left[(1-\gamma) \alpha_{i}\right]^{\frac{1-\gamma}{\gamma}}}\right]^{\frac{\varsigma}{1+\varsigma}} \varrho\left(p, \phi_{i}, \bar{k}_{i}\right)
$$

Hence the result.

Proposition 3 uncovers the determinants of the demand for trafficked children in each State $i$. In particular, two important remarks can be derived from (54) by way of differentiation.

Remark 7. If condition (50) holds, then the demand for trafficked children decreases with an exogenous increase in the market price, $p$ : $\partial n_{i d} / \partial p<0$.

Remark 8. The demand for trafficked children is higher the wealthier the country: $\partial n_{i d} / \partial \bar{k}_{i}>0$.

The latter remark is consistent with empirical observations showing that the major routes of transboundary child trafficking have poorer countries as the source, and richer countries as the destination, of trafficked children (UNICEF 2008).

On the basis of Proposition 3, we can therefore complete the construction of the global excess demand function as follows using (53):

$$
\chi\left(p, \phi_{A}, \phi_{B}, \bar{k}_{A}, \bar{k}_{B}\right)=\sum_{i} N^{d}\left(p, \phi_{i}, \bar{k}_{i}\right)-\sum_{i} N^{o}\left(p, \phi_{i}, \bar{k}_{i}\right) .
$$

Hence the following Proposition:

Proposition 4. Let condition (52) hold. Then the global excess demand function for trafficked children is a strictly decreasing function of the price, $p$.

Proof. The result follows from Remarks 5 and 7, noting that condition (52) implies condition (33).

In this convex environment, Proposition 4 may be sufficient to ensure that a global market equilibrium exists.

Definition 2. A global market equilibrium is a price $p^{*}$ for a trafficked child such that given the state of the world as described by the vector $\left(\phi_{A}, \phi_{B}, \bar{k}_{A}, \bar{k}_{B}\right)$,

$$
\chi\left(p^{*}, \phi_{A}, \phi_{B}, \bar{k}_{A}, \bar{k}_{B}\right) \equiv 0 .
$$


Let $p^{*}=P\left(\phi_{A}, \phi_{B}, \bar{k}_{A}, \bar{k}_{B}\right)$ denote the equilibrium relative price of a trafficked child when the state of nature is characterized by the vector of fundamentals. On the basis of this equilibrium, we can rewrite the incidence of child trafficking in state $i$ as follows using (51):

$$
n_{i u}^{*}=\frac{\lambda_{i}\left(1+g_{i u}\right)^{\frac{1}{1+\varsigma}}\left[P\left(\phi_{A}, \phi_{B}, \bar{k}_{A}, \bar{k}_{B}\right)\right]^{-\frac{1}{(1+\varsigma) \gamma}}}{P\left(\phi_{A}, \phi_{B}, \bar{k}_{A}, \bar{k}_{B}\right)+\left(1+g_{i u}\right)^{\frac{1}{1+\varsigma}}\left[P\left(\phi_{A}, \phi_{B}, \bar{k}_{A}, \bar{k}_{B}\right)\right]^{-\mu} \bar{k}_{i} a_{i}-\alpha_{i} T_{i}},
$$

all $i$.

Then observe from (61) how the incidence of child trafficking in state $i$ is affected by the fundamentals of state $j$, as determined by the pair $\left(\phi_{j}, \bar{k}_{j}\right), i \neq j$, with $i, j=A, B$. This dependence of the equilibrium incidence of child trafficking in state $i$ on both the level of economic development and policy action in state $j$ implies the existence of crosscountry externalities. Because of these externalities, efficiency in the fight against child trafficking can be enhanced by international coordination of national Action plans against child trafficking between states.

\subsection{The Global Incidence of Child Trafficking}

In this subsection, we characterize the determinants of the global incidence of child trafficking. Just to recall, our environment consists of two states, $A$ and $B$. The structure of this environment will be said to be symmetric if the two states have the same level of wealth: $\bar{k}_{A}=\bar{k}_{B}=\bar{k}$. This environment will be said to exhibit state heterogeneity if $\bar{k}_{A} \neq \bar{k}_{B}$.

Recall also that we assumed above that there is an international planner who has perfect knowledge of each national government's budget constraint, so that the only object of international coordination is the vector of shares of public funds allocated to fighting child trafficking on the upstream front, $\left(\phi_{A}, \phi_{B}\right)$, where $\left(1-\phi_{A}, 1-\phi_{B}\right)$ denotes the corresponding vector of shares allocated to fighting child trafficking on the downstream front.

We know that the global incidence of child trafficking and exploitation, $n_{t}=\eta\left(\phi_{A}, \phi_{B}, \bar{k}_{A}, \bar{k}_{B}\right)$, is the sum total of states' incidences. Using (61), we know that this global incidence is given by:

$$
n_{t}=\sum_{i}\left[\frac{\lambda_{i}\left(1+g_{i u}\right)^{\frac{1}{1+\varsigma}}\left[P\left(\phi_{A}, \phi_{B}, \bar{k}_{A}, \bar{k}_{B}\right)\right]^{-\frac{1}{(1+\varsigma) \gamma}}}{P\left(\phi_{A}, \phi_{B}, \bar{k}_{A}, \bar{k}_{B}\right)+\left(1+g_{i u}\right)^{\frac{1}{1+\varsigma}}\left[P\left(\phi_{A}, \phi_{B}, \bar{k}_{A}, \bar{k}_{B}\right)\right]^{-\mu} \bar{k}_{i} a_{i}-\alpha_{i} T_{i}}\right] .
$$


Therefore the goal of international cooperation is to minimize $\eta\left(\phi_{A}, \phi_{B}, \bar{k}_{A}, \bar{k}_{B}\right)$ by the choice of the policy actions' pair, $\left(\phi_{A}, \phi_{B}\right)$, given the fundamentals of the global economy, $\left(\bar{k}_{A}, \bar{k}_{B}\right)$. In other words, the cooperative equilibrium provides a prescription of policy actions by the government of each state-parties, in the form of the vector of relative shares of public funds allocated to the upstream battle against child trafficking, $\left(\phi_{A}^{*}, \phi_{B}^{*}\right)$. This pair of shares is solution to the following minimization problem:

$$
\min _{\left\langle\phi_{A}, \phi_{B}\right\rangle} \eta\left(\phi_{A}, \phi_{B}, \bar{k}_{A}, \bar{k}_{B}\right)
$$

For the purpose of this analysis, the questions we are interested in are the following: What are the properties of the cooperative equilibrium? Does this equilibrium prescribe that all national action plans against child trafficking be symmetric (i.e., $\phi_{A}=\phi_{B}$ )? In other words should the governments of all countries do the same thing? Or, should national action plans be asymmetric, with one state focusing more on the upstream front and the other on the downstream (i.e., $\left.\phi_{A} \neq \phi_{B}\right)$ ? We address these questions in the following sub-section.

\section{International Cooperation}

In this section, we characterize a cooperative equilibrium between state-parties. We consider two case-scenarios. In the first, parental investment and public investment are strategic substitute in the fight against upstream trafficking operations $(\varsigma>0)$, while in the second, they are strategic complement $(\varsigma<0)$.

\subsection{Properties of the Cooperative Equilibrium under Strategic Substitutability: $\varsigma>0$}

The cooperative equilibrium is defined as the solution of the minimization program defined in (63). Solving this optimization program yields a characterization of the main feature of international coordination of national policy responses against child trafficking. To uncover the properties of the cooperative equilibrium, we consider three types of cooperation: (a) cooperation between poorer countries, (b) between richer countries, and (c) between a richer country and a poorer one. We also normalize $\varsigma$ to unity, i.e., $\varsigma=1$.

\subsubsection{Cooperation between Poorer Countries}

Both countries are equally poor. This implies that they have a smaller stock of physical capital: $\bar{k}_{A}=\bar{k}_{B}=1$. This leads to the following expression for the global incidence of child trafficking: 


$$
\hat{\eta}\left(\phi_{A}, \phi_{B}\right)=\sum_{i}\left[\frac{\lambda_{i}\left(1+g_{i u}\right)\left[\bar{P}\left(\phi_{A}, \phi_{B}\right)\right]^{-\frac{1}{\gamma}}}{P\left(\phi_{A}, \phi_{B}\right)+\left(1+g_{i u}\right)\left[P\left(\phi_{A}, \phi_{B}\right)\right]^{\frac{\gamma-2}{\gamma}} a_{i}-\alpha_{i} \beta}\right] .
$$

In this case, and in the absence of international coordination, any cross-country differences in the incidence of child trafficking will be fully explained by cross-country differences in the structure of the national action plans against child trafficking as determined by the combination of shares $\left(\phi_{A}, \phi_{B}\right)$. The problem of international coordination of national action plans can thus be defined as follows:

$$
\min _{\left\langle\phi_{A}, \phi_{B}\right\rangle} \hat{\eta}\left(\phi_{A}, \phi_{B}\right)
$$

To characterize the cooperative equilibrium, we simulate the model by assigning numerical values to the relevant parameters. We select $\gamma, \beta, \epsilon, \bar{\theta}, \varepsilon_{u}$, and $\varepsilon_{d}$ such that condition (52) holds, which also implies that condition (50) will hold. Table 1 below lists values for $\gamma, \beta, \epsilon, \bar{\theta}, \varepsilon_{u}$, and $\varepsilon_{d}$, and reports computed values for the cooperative equilibrium's policy pair, $\left(\phi_{A}, \phi_{B}\right)$, and for the global incidence of child trafficking,

\begin{tabular}{|c|c|c|c|c|c|c|c|}
\hline Tal & . & abst & t & lit & (c) & 1): & $=\bar{k}_{B}=1$ \\
\hline$\gamma$ & $\beta$ & $\epsilon$ & $\overline{\bar{\theta}}$ & $\varepsilon_{u}$ & $\varepsilon_{d}$ & $\left(\phi_{A}^{*}, \phi_{B}^{*}\right)$ & $\min \hat{\eta}()$. \\
\hline 0.4 & 0.1 & 0.1 & 0.1 & 1 & 1 & $(1,1)$ & 0.1064 \\
\hline
\end{tabular}
$\min \hat{\eta}($.$) .$

Fig. 1 below plots the global incidence of child trafficking, $\hat{\eta}\left(\phi_{A}, \phi_{B}\right)$, for various levels of the policy pair $\left(\phi_{A}, \phi_{B}\right)$ :

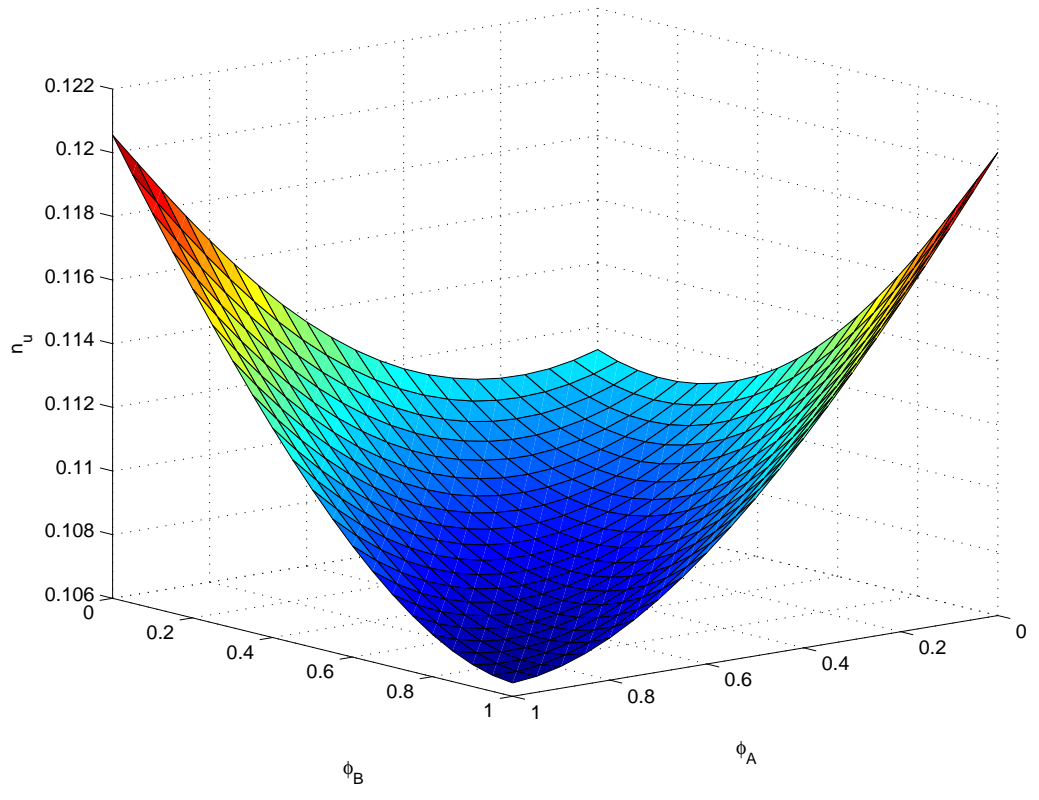

Figure 1. Cooperation between poorer countries: Substitutability 
The following result can be derived from Fig. 1 above:

Result 1. When parental and government actions are strategic substitutes in the fight against the supply of trafficked children, the unique cooperative equilibrium between two poorer countries involves both countries simultaneously attacking the supply of child trafficking (i.e., $\left.\left(\phi_{A}, \phi_{B}\right)=(1,1)\right)$.

For any two countries that are structurally similar, each one of them can be both a source and a destination for trafficked children. Cooperation is beneficial in this case, simply because it corrects externalities arising from the transboundary nature of the child trafficking phenomenon. Because both countries are equally poor, they have in common a high incidence of child vulnerability to trafficking and a relatively low demand for trafficked children. While a low demand may tend to make upstream child trafficking activities less profitable, the high incidence of child vulnerability to trafficking, however, will tend to raise the degree of profitability of these upstream operations. As a result, despite parents' tendency to substitute private protection with public protection of vulnerable children, specializing public resources in the fight against upstream child trafficking operations is the best pattern of cooperation between poorer countries, because it combines with a lower demand for trafficked children to reduce the profitability of upstream operations.

\subsubsection{Cooperation between Richer Countries}

Richer countries are those with a stock of capital $\bar{k}_{A}=\bar{k}_{B}=5$. In that case, the objective function for global incidence

$$
\hat{\eta}\left(\phi_{A}, \phi_{B}\right)=\sum_{i}\left[\frac{\lambda_{i}\left(1+g_{i u}\right)\left[\bar{P}\left(\phi_{A}, \phi_{B}\right)\right]^{-\frac{1}{\gamma}}}{P\left(\phi_{A}, \phi_{B}\right)+5\left(1+g_{i u}\right)\left[P\left(\phi_{A}, \phi_{B}\right)\right]^{\frac{\gamma-2}{\gamma}} a_{i} \bar{k}-\alpha_{i} \beta \bar{k}^{\epsilon}}\right]
$$

We maintain the values of the parameters $\gamma, \beta, \epsilon, \bar{\theta}, \varepsilon_{u}$, and $\varepsilon_{d}$ as set in Table 1 above, so that he minimization problem in (63) is well-defined and condition (50) holds. Table 2 below reports the cooperative equilibrium policy pair, $\left(\phi_{A}, \phi_{B}\right)$, as well as the global incidence of child trafficking that is supported as the cooperative equilibrium:

\begin{tabular}{c|c|c|c|c|c|c|c}
\hline \multicolumn{6}{c}{ Table 2: Substitutability $(\varsigma=1): \quad \bar{k}_{A}=\bar{k}_{B}=5$} \\
\hline \hline$\gamma$ & $\beta$ & $\epsilon$ & $\bar{\theta}$ & $\varepsilon_{u}$ & $\varepsilon_{d}$ & $\left(\phi_{A}^{*}, \phi_{B}^{*}\right)$ & $\min \hat{\eta}()$. \\
\hline 0.4 & 0.1 & 0.1 & 0.1 & 1 & 1 & $(1,0)$ or $(0,1)$ & 0.0358 \\
\hline
\end{tabular}

Fig. 2 below plots the global incidence of child trafficking, $\hat{\eta}\left(\phi_{A}, \phi_{B}\right)$, for various levels of the policy vector, $\left(\phi_{A}, \phi_{B}\right)$. 


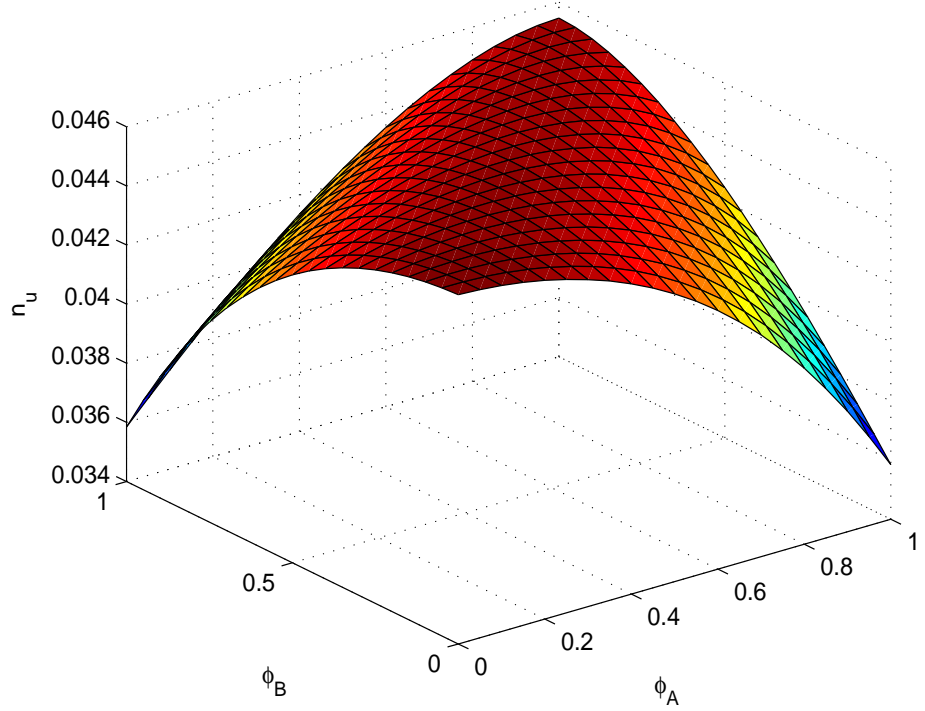

Figure 2. Cooperation between richer countries: Substitutability

The following results can be derived from inspection Fig. 2:

Result 2. When parental and government actions are strategic substitutes in the fight against the supply of trafficked children, cooperation between richer countries yields two asymmetric equilibria. In each equilibrium, one country completely specializes public intervention to the fight against the supply of trafficked children while the other specializes it to the fight against the demand. (i.e., either $\left(\phi_{A}, \phi_{B}\right)=(1,0)$ or $\left(\phi_{A}, \phi_{B}\right)=(0,1)$.

Here again, both countries are structurally similar. Cooperation in this case simply corrects the cross-country externalities. This leads to a pattern of specialization characterized by multiple equilibria. However, unlike the case of cooperation between poorer countries, in this case, cooperation always leads to asymmetric national action plans.

\subsubsection{Cooperation between Richer and Poorer Countries}

In this subsection we consider a world made up of a poorer country and a richer one. We want to know what happens to the properties of the cooperative equilibrium when the economy of one of the states is poorer than the other. In our model, we posit that country $B$ is relatively poorer than country $A$ : $\bar{k}_{B}<\bar{k}_{A}$.

We simulate the model in the same manner as above. We set $\bar{k}_{A}=5$ and $\bar{k}_{B}=1$. We maintain the levels of $\gamma, \beta, \epsilon, \bar{\theta}, \varepsilon_{u}$, and $\varepsilon_{d}$ used in the previous case, so that the minimization problem in (63) is well-defined and condition (50) holds. Table 3 lists the values of these parameters, and also reports computed values for the policy actions' pair $\left(\phi_{A}, \phi_{B}\right)$ as well as the global incidence of child trafficking, $\min \hat{\eta}($.$) :$ 


\begin{tabular}{|c|c|c|c|c|c|c|c|}
\hline Tab & & $\mathrm{b} b \mathrm{~s}$ & $\mathrm{u}$ & & & 1): & $5 ; \quad \bar{k}_{B}$ \\
\hline$\gamma$ & $\beta$ & $\epsilon$ & $\overline{\bar{\theta}}$ & $\varepsilon_{u}$ & $\varepsilon_{d}$ & $\left(\phi_{A}^{*}, \phi_{B}^{*}\right)$ & $\min \hat{\eta}()$. \\
\hline 0.4 & 0.1 & 0.1 & 0.1 & 1 & 1 & $(1,0)$ & 0.0476 \\
\hline
\end{tabular}

The unique cooperative equilibrium features asymmetric national action plans: $\left(\phi_{A}^{*}, \phi_{B}^{*}\right)=(1,0)$.

Fig. 3 below plots the global incidence of child trafficking against the policy pair $\left(\phi_{A}, \phi_{B}\right)$ when international cooperation to curb child trafficking involved a richer country and a poorer one:

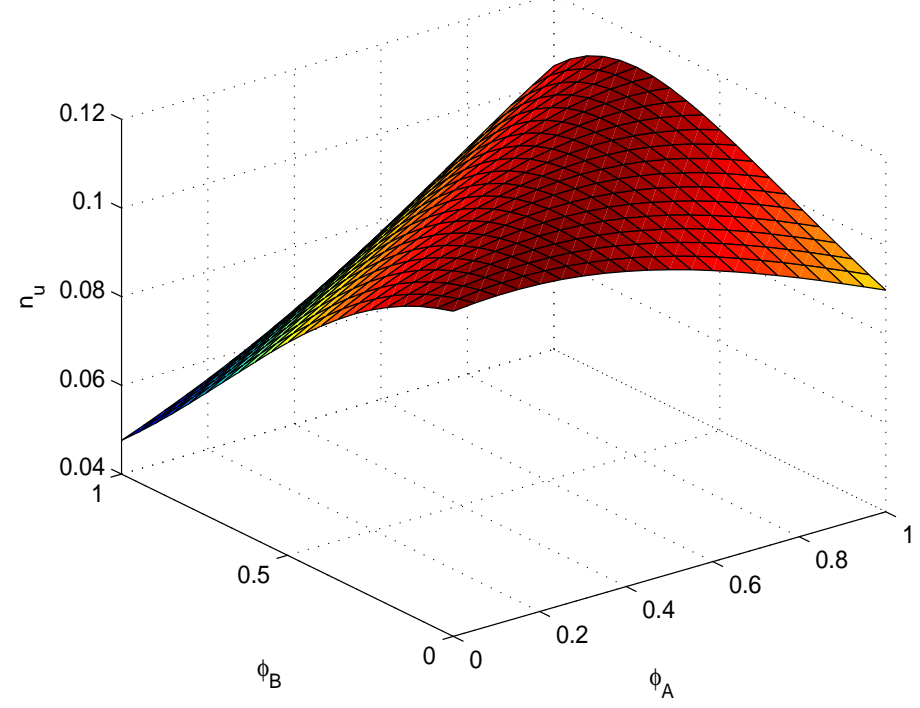

Figure 3. Cooperation between rich and poor countries: Substitutability

The following result can be derived from inspection of Fig.3:

Result 3. In a world made up of a richer country and poorer one, the cooperative equilibrium has the following properties: (i) specialization between the two states is complete; (ii) the poorer state specializes its intervention on the upstream battlefront to mitigate the supply of trafficked children (i.e., $\phi_{B}=1$ ), while the richer state focuses on the downstream battlefront to mitigate the demand for trafficked children (i.e., $\phi_{A}=0$ ).

Unlike in previous two cases where the two economies have an identical structure, in this asymmetric case, one economy is richer $(A)$ than the other $(B)$. The supply of trafficked children is higher in the poorer economy $(B)$ while the demand for trafficked children is higher in the richer one $(A)$. To the extent that child trafficking is a 
transboundary phenomenon, the high incidence of child vulnerability to trafficking in the poorer country generates a negative externality in the fight against demand in the richer country while the high demand for trafficked children in the richer country generates a negative externality in the fight against supply in the poorer country. Therefore, international cooperation best internalizes these cross-country externalities by mandating a pattern of complete specialization whereby the poorer country attacks the supply while the richer country attacks the demand, despite the strategic substitutability.

The above results $(1,2$, and 3$)$ are obtained in the context where parental and government actions in the upstream battlefront against child trafficking are strategic substitutes. From an empirical point of view, however, it is not clear whether such substitutability is supported by the data. Therefore, it might be of interest to ask what the properties of the cooperative equilibrium would be if parental and government actions in the upstream battlefront against child trafficking were strategic complements instead. We undertake this task below.

\subsection{Properties of the Cooperative Equilibrium under Strategic Complementarities: $\varsigma<0$}

In this section, we explore the features of the cooperative equilibrium in the context where public funds and parental resources are strategic complements in the fight against upstream child trafficking operations. From (12), this amounts to setting $\varsigma<0$. We specialize our analysis to the case where $\varsigma=-1 / 2$. As in the case with strategic substitutability, we consider three different forms of cooperation: (a) between two poorer countries, (b) between two equally rich countries, (c) between a richer country and a poorer one.

\subsubsection{Cooperation between Poorer Countries}

As in the case with strategic substitutability, for poorer countries, we set $\bar{k}_{A}=\bar{k}_{B}=1$. We maintain all the other parameters at the same levels as in the substitutability case. Table 4 below reports computed values for the policy pair $\left(\phi_{A}, \phi_{B}\right)$ as well as the global incidence of child trafficking, $\min \hat{\eta}($.$) :$

\begin{tabular}{c|c|c|c|c|c|c|c}
\hline \multicolumn{7}{c}{ Table 4: Complementarity $(\varsigma=-1 / 2):$} & $\bar{k}_{A}=\bar{k}_{B}=1$ \\
\hline \hline$\gamma$ & $\beta$ & $\epsilon$ & $\bar{\theta}$ & $\varepsilon_{u}$ & $\varepsilon_{d}$ & $\left(\phi_{A}^{*}, \phi_{B}^{*}\right)$ & $\min \hat{\eta}()$. \\
\hline 0.4 & 0.1 & 0.1 & 0.1 & 1 & 1 & $(1,1)$ & 0.0827 \\
\hline
\end{tabular}

Fig. 4 below is built using parameter values presented in Table 4, and plots the global incidence of child trafficking against the policy pair, $\left(\phi_{A}, \phi_{B}\right)$. 


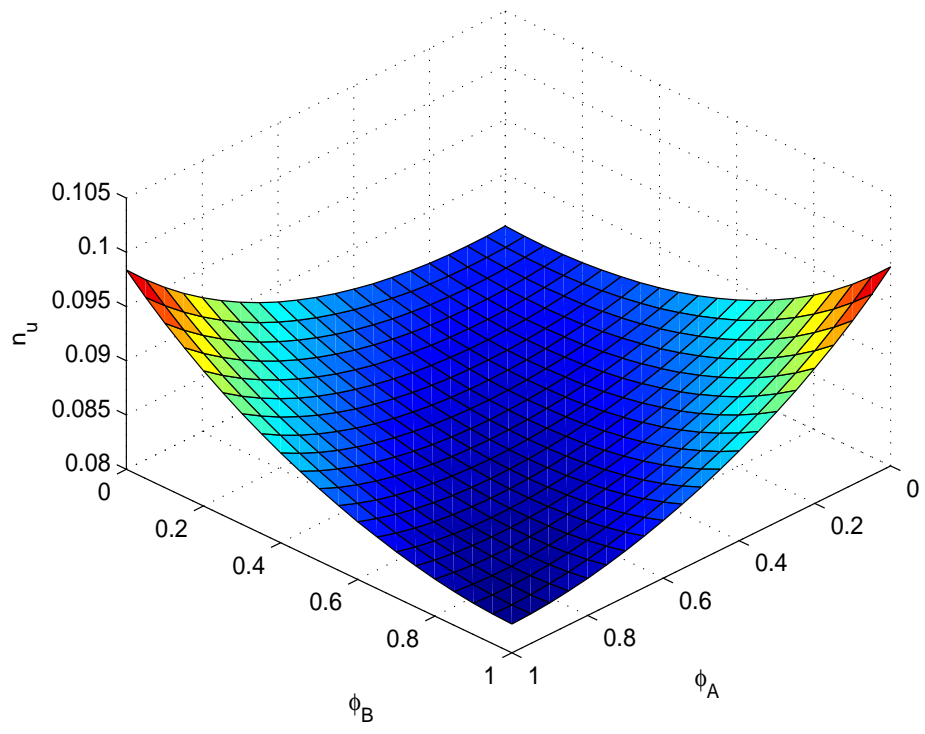

Figure 4. Cooperation between poorer countries: Complementarity

The pattern of specialization is the same as in the case of substitutability: both countries simultaneously attack the supply of child trafficking. I.e., $\left(\phi_{A}, \phi_{B}\right)=(1,1)$ as can be seen from Fig. 4. However, the incidence of child trafficking is lower under complementarity than under substitutability. (See Table 1 and Table 4).

\subsubsection{Cooperation between Richer Countries}

Here again we consider a world where both countries are richer, i.e., $\bar{k}_{A}=\bar{k}_{B}=5$. All other parameters are set at values identical to those of the substitutability case. Table 5 below reports computed values for the policy pair, $\left(\phi_{A}, \phi_{B}\right)$, as well as the global incidence of child trafficking, $\min \hat{\eta}($.$) :$

\begin{tabular}{c|c|c|c|c|c|c|c}
\hline \multicolumn{6}{c}{ Table 5: Complementarity $(\varsigma=-1 / 2):$} & $\bar{k}_{A}=\bar{k}_{B}=5$ \\
\hline \hline$\gamma$ & $\beta$ & $\epsilon$ & $\bar{\theta}$ & $\varepsilon_{u}$ & $\varepsilon_{d}$ & $\left(\phi_{A}^{*}, \phi_{B}^{*}\right)$ & $\min \hat{\eta}()$. \\
\hline 0.4 & 0.1 & 0.1 & 0.1 & 1 & 1 & $(1,0) ;(0,1)$ & 0.0203 \\
\hline
\end{tabular}

Like in the corresponding substitutability case, there are two cooperative asymmetric equilibria: One where $A$ specializes in the fight against supply and $B$ in the fight against demand (i.e., $\left.\left(\phi_{A}, \phi_{B}\right)=(1,0)\right)$ and the other where it is the reverse (i.e., $\left(\phi_{A}, \phi_{B}\right)=$ $(0,1))$. Fig. 5 below plots the global incidence of child trafficking against the policy pair, $\left(\phi_{A}, \phi_{B}\right)$ : 


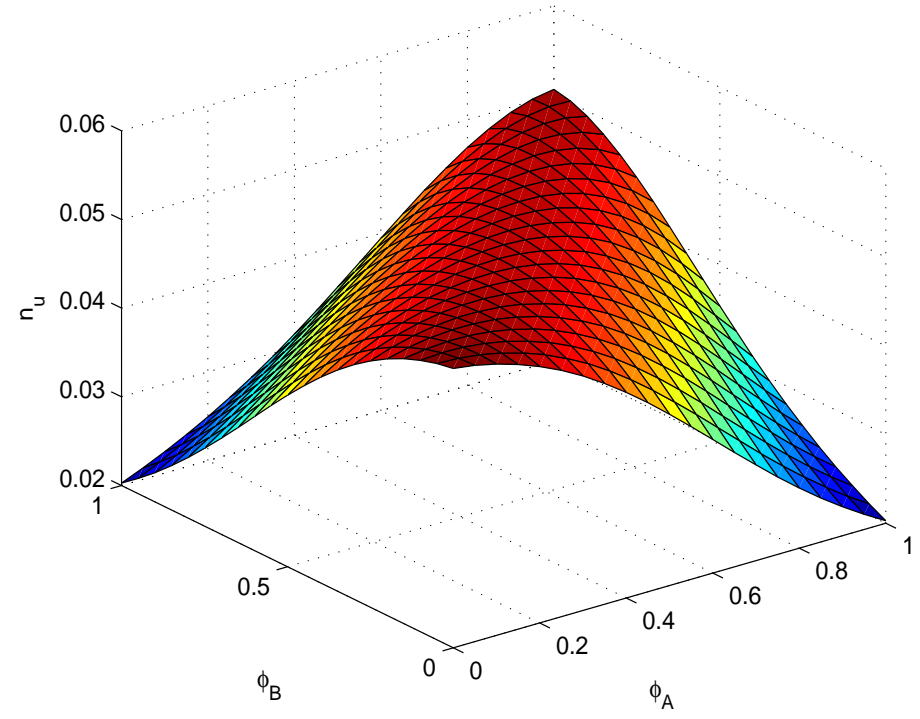

Figure 5. Cooperation between richer countries: Complementarity

The two cooperative equilibria can be seen at each lower corner of the graph, corresponding to the lowest global incidence of child trafficking. The only difference between this case and the corresponding case under strategic substitutability pertains to the global incidence of child trafficking. A comparison between Table 2 and Table 5 reveals that the global incidence of child trafficking is lower under complementarity than under substitutability.

\subsubsection{Cooperation with Asymmetric Countries}

In this case scenario, we make country $B$ relatively poorer that country $A$, which in this model simply means, $\bar{k}_{B}<\bar{k}_{A}$. We set $\bar{k}_{A}=5$ and $\bar{k}_{B}=1$, and also maintain all other parameters at their levels in Table 3. Table 6 below reports the cooperative equilibrium, $\left(\phi_{A}^{*}, \phi_{B}^{*}\right)$, as well as the global incidence of child trafficking - the outcome of this cooperative equilibrium.

\begin{tabular}{|c|c|c|c|c|c|c|c|}
\hline \multicolumn{8}{|c|}{ Table 6: Complementarity $(\varsigma=-1 / 2): \quad \bar{k}_{A}=5 ; \quad \bar{k}_{B}=1$} \\
\hline$\gamma$ & $\beta$ & $\epsilon$ & $\overline{\bar{\theta}}$ & $\varepsilon_{u}$ & $\varepsilon_{d}$ & $\left(\phi_{A}^{*}, \phi_{B}^{*}\right)$ & $\min \hat{\eta}()$. \\
\hline 0.4 & 0.1 & 0.1 & 0.1 & 1 & 1 & $(0,1)$ & 0.0198 \\
\hline
\end{tabular}

Fig. 6 below illustrates the unicity of the cooperative equilibrium. 


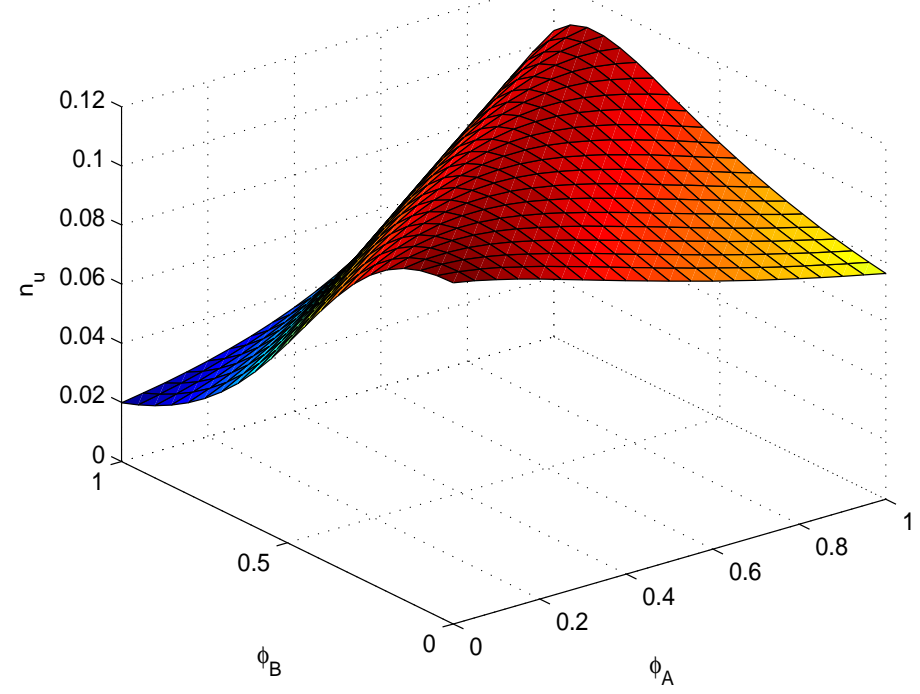

Figure 6. Cooperation between between rich and poor countries: Complementarity

This result is analogous to the one obtain for the asymmetric case under the strategic substitutability between public funds and parental resources in the fight against child vulnerability to trafficking. The only difference pertains to the global incidence of child trafficking. Complementarity makes it lower than substitutability, but does not change the pattern of specialization. Our analysis therefore suggests that the rational for international cooperation in the global fight against child trafficking stems from the gain from complete specialization of each state party. 


\section{Conclusion}

In this paper, we use a two-country general equilibrium model of child trafficking to explore the pillars of international cooperation in the battle against transboundary child trafficking. Our model highlights a triple line of defense against child trafficking, one of which is privately funded while the other two are publicly funded. The first line of defense consists of parental investment in child protection against vulnerability to trafficking. We show that at this first line of the battle against child trafficking, parental wealth determines success. Vulnerable children are therefore those whose parents cannot afford to allocate household resources to child protection. This creates an incentive for the government to set up two additional lines of defense: one designed to curb the traffickers predatory attacks on vulnerable children (upstream battlefront) and another designed to curb activities using trafficked children (downstream battle front). Because of the transboundary nature of the market for trafficked children, in a market equilibrium, the incidence of child trafficking in any country depends on domestic factors (including the level of economic development and the government policy) as well as external factors (including the level of economic development of and government policy in, foreign countries).

The goal of international cooperation is therefore to correct these cross-country externalities while its object is the prescription of the share of public funds the government of each cooperating country is to allocate to each of the two battlefronts. International cooperation is formalized as a cooperative equilibrium, defined as the policy actions' pair that minimizes the global incidence of child trafficking. We show that complete specialization between state parties is a central property of a cooperative equilibrium. We argue that the pattern of specialization is unaffected by whether or not parental and government investments are strategic complements in the fight against the supply of trafficked children. The only determinant of the pattern of specialization is the level of economic development of state-parties. We show that specialization features asymmetric national action plans when countries are structurally different or when they are sufficiently rich. In particular, when countries are structurally different, the unique cooperative equilibrium exhibits a pattern of complete specialization whereby the government of the richer country completely specializes its policy intervention on the demand for child trafficking within its territory while the government of the poorer country completely specializes its policy intervention on the supply of trafficked children from its territory. We conclude that international organizations focusing on the elimination of child trafficking (e.g., UNICEF, ILO) should emphasize a pattern of specialization featuring asymmetric national action plans between richer and poorer countries. 


\section{References}

[1] Barrett, Scott, 2001. International Cooperation for Sale. European Economic Review $60,1835-1850$.

[2] Barrett, Scott, 2003. Environment and statecraft. Oxford University Press, Oxford.

[3] Basu, Kaushik and P.H. Van (1998). The Economics of Child Labor. American Economic Review 88(3), 412 - 27.

[4] Besler, Patrick, 2005. Forced Labour and Human Trafficking: Estimating the Profits, Working Paper. International Labour Office, Geneva.

[5] Boucher, Vincent and Yann Bramoullé, 2010. Providing Global Public Goods under Uncertainty. Journal of Public Economics 94, 591-603.

[6] Dessy, Sylvain and Stéphane Pallage, 2005. A Theory of the Worst Forms of Child Labor. Economic Journal, vol. 115(500), 68-87.

[7] ILO-IPEC, 2009. Training manual to fight trafficking in children for labour, sexual and other forms of exploitation / International Labour Office, International Programme on the Elimination of Child Labour (IPEC). Geneva: ILO, 2009 - 4 v.

[8] Rogers, Carol Ann and Kenneth A. Swinnerton, 2008. A Theory of Exploitative Child Labor. Oxford Economic Papers, Vol. 60(1), 20-41.

[9] UNICEF-IRC, 2008. Child Trafficking in Europe: A Broad Vision to Put Children First.

[10] UNICEF-IRC, 2009. South-Asia in Action: Preventing and Responding to Child Trafficking. Innocenti Research Center. Available online at http://www.unicefirc.org/publications/pdf/ii_ct_southasia_analysis.pdf. 